\title{
MINYAK ATSIRI UNTUK PENGENDALIAN MIKROORGANISME PADA SITUS CANDI SUROWONO
}

\section{ESSENTIAL OILS FOR CONTROLING MICROORGANISM ON SUROWONO TEMPLE SITE}

\author{
Fransiska Dian Ekarini ${ }^{1}$, Agus Kiswanto ${ }^{2}$, Yuli Fatmawati ${ }^{3}$ \\ Balai Konservasi Borobudur', Balai Pelestarian Cagar Budaya Jawa Timur², \\ Balai Pelestarian Cagar Budaya Jawa Timur ${ }^{3}$ \\ fransiska.dian@kemdikbud.go.id
}

\begin{abstract}
ABSTRAK
Situs Candi Surowono yang lokasinya berada di alam terbuka sangat rentan terhadap kerusakan dan pelapukan. Salah satu penyebab kerusakan dan pelapukan batu andesit penyusun Candi Surowono adalah adanya organisme berupa lumut (moss) dan lumut kerak (lichen), organisme ini apabila tidak dikendalikan maka lama kelamaan akan menyebabkan degradasi kekuatan batu Candi Surowono. Salah satu upaya untuk pengendalian organisme ini digunakan bahan alam yaitu minyak atsiri sebagai alternatif pengganti bahan kimia yang selama ini dipakai. Keunggulan penggunaan bahan alam ini adalah selain bahannya yang mudah didapat juga ramah lingkungan dan tidak beracun. Minyak atsiri yang dipakai adalah sereh wangi, pala dan cengkeh. Pemakaiannya dalam bentuk emulsi yaitu dicampurkan dengan surfaktan (tween 80) dan akuades. Konsentrasi masingmasing emulsi minyak atsiri adalah 10\%. Pengaplikasian bahan emulsi minyak atsiri dengan cara semprot (spray) pada permukaan batu andesit yang ditumbuhi mikroorganisme. Hasil pengaplikasian menunjukkan bahwa emulsi minyak atsiri sereh wangi dan cengkeh efektif untuk membersihkan lumut (moss), sedangkan untuk membersihkan lumut kerak (lichen) paling efektif menggunakan emulsi minyak atsiri cengkeh.
\end{abstract}

Kata Kunci: Bahan alam; minyak atsiri; mikroorganisme; Candi Surowono

\section{ABSTRACT}

The Surowono Temple site, which is located in the open space, is very vulnerable to damage and weathering. One of the causes of damage and weathering of the andesite stones composed the Surowono Temple is the presence of organisms in the form of moss and lichen. One of the efforts to control these organisms is to use natural product, namely essential oils as an alternative to replace chemicals that have been used so far. The advantage of using this natural material is to being easily available, also environmentally friendly and non-toxic. The essential oils used are citronella, nutmeg and cloves. Its use is in the form of an emulsion, which is mixed with surfactant (tween 80) and distilled water. The concentration of each essential oil emulsion was $10 \%$. Application of essential oil emulsion by spraying on the surface of andesite stone overgrown with microorganisms. The results of the application showed that the essential oil emulsion of citronella and cloves was effective for cleaning the moss, while for cleaning the lichen the most effective was using clove essential oil emulsion.

Keywords: Natural materials; essential oil; mecroorganisms; Surowono temple 


\section{PENDAHULUAN}

Indonesia merupakan negara tropis yang memiliki suhu udara dan kelembaban udara yang tinggi. Hal ini menyebabkan tumbuhnya keanekaragaman hayati yang banyak. Kondisi suhu udara dan kelembaban udara yang tinggi disukai oleh mikroorganisme terutama lumut (moss) dan lumut kerak (lichen). Pada sebuah bangunan candi yang tersusun dari batu andesit sering dijumpai organisme berupa lumut dan lichen. Lumut dan lichen ini memiliki rizoid yang digunakan untuk menempel pada substrat batu dan masuk ke pori-pori batu sehingga apabila tidak dibersihkan dapat mempercepat degradasi kekuatan batu.

Lumut (moss) merupakan tanaman yang banyak dijumpai di sekitar kita. Biasanya organisme ini menyukai lingkungan yang lembab dengan penyinaran yang cukup. Lumut adalah organisme yang termasuk kelam kondom plantae yang memiliki karakteristik khas yakni tidak mempunyai jaringan vaskuler dan akar sejati namun memiliki rhizoid (Purawijaya and Priyantika 2013) Pembagian jenis lumut berdasarkan divisi meliputi lumut daun (Bryopsida), lumut hati (Hepaticopsida), dan lumut tanduk (Anthocerotopsida) (Waldi 2017). Tumbuhan lumut memiliki bagian akar yang disebut rizoid yang digunakan untuk menempel pada substrat baik pada batu, kayu dan lainnya.

Lumut kerak (lichen) merupakan tanaman simbo sis dari ganggang (algae) dan jamur (fungt). Dua organisme ganggang dan jamur ini berasosiasi membentuk satu organisme yaitu lumut kerak (lichen). Penyusun organisme jamur disebut Mycobiont yang umumnya berasal dari kelas Ascomycetes dan dua atau tiga genus termasuk kelas Basidiomycetes sedangkan penyusun komponen ganggang disebut Phycobiont, yang berasal dari divisi alga biru-hijau (Chyanophyceae) atau alga hijau (Chlorophyta) (Pratiwi 2006). Berdasarkan morfologi talus lumut kerak dibedakan menjadi empat bentuk (Rosentreter, Bowker, and Belnap 2007) yaitu (1) Crustose, memiliki talus yang umumnya berukuran kecil, datar, tipis dan selalu melekat pada permukaan batu, kulit pohon atau tanah sehingga tidak mudah untuk dicabut tanpa merusak substratnya; (2) Foliose, memiliki struktur daun yang tersusun oleh lobus-lobus, ciri tallusnya datar, lebar, banyak lekukan seperti daun yang mengkerut dan berputar; (3) Fruticose, memiliki talus berupa semak dan memiliki banyak cabang berbentuk seperti pita; (4) Squamulose, memiliki lobus-lobus seperti sisik, biasanya berukuran kecil dan saling tindih serta saling memiliki struktur tubuh buah yang disebut podetia. Lumut kerak merupakan tumbuhan pioner yang dapat tumbuh di tempat yang ekstrem. Lumut kerak ini memerlukan substrat sebagai tempat untuk tumbuh. Berdasarkan habitatnya lumut kerak dibagi menjadi 3 yaitu: Saxicolous, yaitu jenis lichen yang hidup di batuan; (2) Corticolous, yaitu lichen yang hidup pada kulit pohon dah terbatas pada daerah tropis dan subtropis yang sebagian besar kondisi lingkungannya lembab; (3) Terricolous, yaitu jenis lichen terrestrial yang hidup di permukaan tanah. Lumut kerak (lichen) merupakan salah satu organisme yang dapat digunakan sebagai indikator pencemaran udara (bioindikator). Bioindikator adalah organisme yang dapat digunakan untuk mengidentifikasi dan menentukan kualitatif pencemaran udara (Conti and Cecchetti 2001).

Selama ini pengendalian lumut dan lichen yang menempel pada bangunan cagar budaya sering menggunakan bahan kimia pabrikan yang banyak tersedia di pasaran. Bahan kimia ini tentu saja memiliki resiko mencemari lingkungan dan merubah warna pada material cagar budaya dan dapat menyebabkan resiko penyakit pada manusia. Penelitian kali ini memakai bahan alam berupa minyak atsiri yang berasal dari tanaman sereh wangi (Cymbopogon nardus), pala (Myristica fragrans) dan cengkeh (Syzygium aromaticum) untuk pembersihan lumut dan lumut kerak. Ketiga bahan alam ini digunakan dalam bentuk emulsi minyak atsiri yang diaplikasikan pada batu andesit di Situs Candi Surowono.

Candi Surowono yang terletak di Dusun Surowono, Desa Canggu, Kecamatan Badas, Kabupaten Kediri, Jawa Timur merupakan peninggalan kerajaan Majapahit pada masa pemerintahan Hayam Wuruk (1351-1389 M). Material penyusun candi berupa batu 
andesit pada bagian atas dan bata pada bagian pondasi dan bagian dalam bangunan. Pada saat ini bangunan yang ada tinggal bagian kaki dan tubuh saja sedangkan bagian atap sudah tidak ada. Di sekitar situs terdapat batu-batu lepas yang kemungkinan merupakan bagian atap candi (BPCB Jawa Timur 2016). Pada struktur bangunan candi dan batu lepas banyak ditumbuhi mikroorganisme terutama lumut dan lumut kerak (lichen). Pemakaian bahan alam untuk pembersihan lumut dan lichen pada Situs Candi Surowono ini sejalan dengan paradigma back to nature dalam penggunaan bahan konservan yang tentu saja lebih ramah lingkungan. Bahan alam ini diharapkan dapat digunakan sebagai alternatif pengganti bahan kimia pabrikan yang selama ini digunakan sehingga dapat menciptakan lingkungan yang bebas dari pencemaran untuk jangka waktu yang panjang.

\section{METODE}

Alat dan bahan

Alat yang digunakan dalam penelitian di Situs Candi Surowono, Desa Canggu, Kecamatan Badas, Kabupaten Kediri ini terdiri dari gelas beker, alat pengaduk, alat semprot, handy microscope (Celestron FlipView-5MP LCD Portable Microscope), weather tracker, plastik penutup, dan sikat lidi. Bbahan yang digunakan meliputi minyak atsiri sereh wangi, minyak atsiri pala, minyak atsiri cengkeh, surfaktan (tween 80), akuades.

\section{Persiapan Bahan}

Persiapan bahan adalah pembuatan emulsi masing-masing minyak atsiri dengan konsentrasi $10 \%$. Pertama, ditentukan terlebih dahulu volume emulsi minyak atsiri yang akan dibuat, semisal akan dibuat volume 1 liter. Setelah itu kita membuat 5\% surfaktan (tween 80) dengan mencampurkan $45 \mathrm{~mL}$ surfaktan (tween 80) dengan $855 \mathrm{~mL}$ akuades, kemudian diaduk hingga homogen. Lalu ditambahkan minyak atsiri sebanyak $100 \mathrm{~mL}$ ke dalam larutan surfaktan dan akuades tersebut, diaduk hingga homogen. Tempatkan masing-masing emulsi minyak atsiri $10 \%$ ke dalam botol semprot dan siap diaplikasikan.

Aplikasi bahan

Ketiga bahan emulsi minyak atsiri diaplikasikan pada batu lepas yang ada di Situs Candi Surowono yang permukaannya ditumbuhi mikroorganisme lumut (moss) dan lumut kerak (lichen).

Identifikasi lumut dan lumut kerak

Identifikasi jenis mikroorganisme terutama jenis lumut (moss) dan lumut kerak (lichen) dilakukan menggunakan alat handy microscope kemudian dilakukan pencarian melalui referensi dari artikel maupun jurnal. Pengambilan sampel pengamatan lumut dan lumut kerak dilakukan secara acak (random sampling).

Rancangan penelitian

Pengumpulan data diawali dengan survei lapangan untuk mengidentifikasi, mengklasifikasi serta menentukan lokasi mikroorganisme khususnya lumut dan lumut kerak yang tumbuh pada batu andesit yang ada di Situs Candi Surowono. Setelah itu, dilakukan pengaplikasian emulsi minyak atsiri sereh wangi $10 \%$, emulsi minyak atsiri pala $10 \%$ dan emulsi minyak atsiri $10 \%$ pada permukaan batu yang ditumbuhi mikroorganisme. Penutupan dengan plastik (cover) pada bagian batu yang diaplikasikan dengan emulsi minyak atsiri diperlukan untuk menghindari air hujan yang dapat melarutkan bahan minyak atsiri dan untuk menghindari penguapan yang berlebih. Penutupan dengan plastik dapat membantu minyak atsiri untuk meresap dan mematikan organisme lumut (moss) dan lumut kerak 
(lichen). Penutupan ini dilakukan selama 3 x 24 jam dan dilakukan pengamatan setiap 24 jam untuk mengetahui efektivitas bahan. Pendokumentasian pada obyek dilakukan pada saat sebelum, selama dan setelah perlakuan. Pengaplikasian ketiga emulsi minyak atsiri diterapkan pada batu lepas yang terdapat di Situs Candi Surowono. Metode analisis data yang digunakan adalah deskriptif kualitatif.

\section{HASIL PENELITIAN}

Pengaplikasian minyak atsiri pada lumut (moss)

Lumut (moss) merupakan tumbuhan tingkat rendah yang tumbuh pada daerah lembab. Warnanya yang hijau mudah dikenali. Pertumbuhan organisme lumut sangat dipengaruhi oleh lingkungan sekitar yaitu suhu udara, kelembaban udara, intensitas cahaya dan ketinggian tempat (Mulyani, Perwati, and Murningsih 2014). Lumut di Situs Candi Surowono banyak tumbuh bauk si tubuh candi terutama bagian kaki dan pada batu lepas di sekitar candi. Untuk dapat mengetahui efektivitas ketiga minyak atsiri yaitu sereh wangi, pala dan cengkeh dalam membersihkan organisme lumut pada batu andesit di Situs Surowono maka untuk pengaplikasiannya dipilih 1 blok batu yang ditumbuhi oleh lumut. Obyek batu yang ditumbuhi lumut dibagi menjadi 4 area yaitu untuk aplikasi emulsi minyak atsiri sereh wangi, pala, cengkeh dan kontrol.
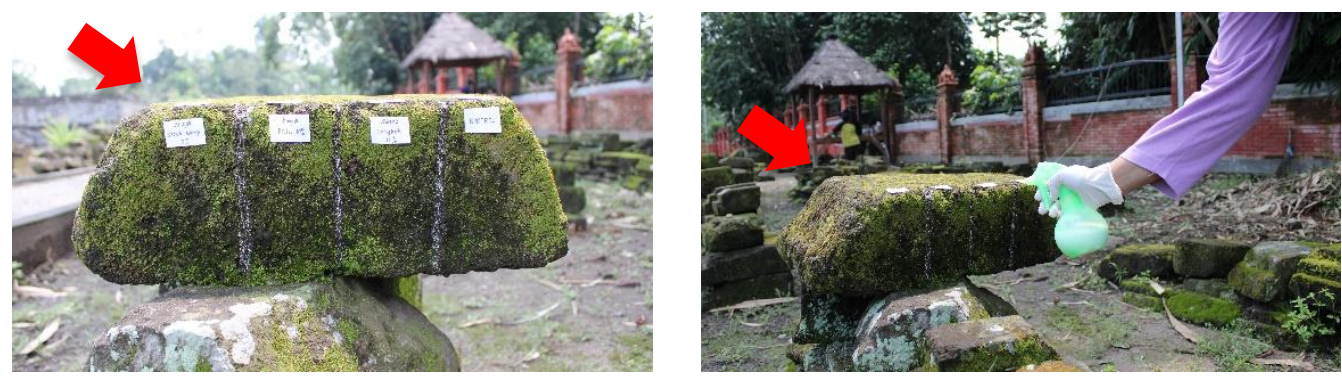

Gambar 1. Gambar Lumut Sebelum Diaplikasi Emulsi Minyak Atsiri (gambar kiri) dan Gambar Lumut yang Disemprot Dengan Emulsi Minyak Atsiri (gambar kanan)

(Sumber: dokumen BPCB Jawa Timur, 2021)

Pada Gambar 1 bagian kiri, batu lepas yang ditumbuhi lumut dibagi menjadi 4 area yang nantinya akan dilakukan pengaplikasian miyak atsiri. Gambar 1 bagian kanan, emulsi minyak atsiri diaplikasikan pada temuan lepas batu andesit yang ditumbuhi oleh organisme lumut (moss) dari paling kiri adalah minyak atsiri sereh wangi, pala, cengkeh dan kontrol. Kontol merupakan area yang tidak diaplikasi oleh emulsi minyak atsiri. Setelah ketiga minyak atsiri disemprotkan kemudian ditutup dengan menggunakan penutup plastik agar terhindar dari air hujan dan penguapan yang berlebih. 

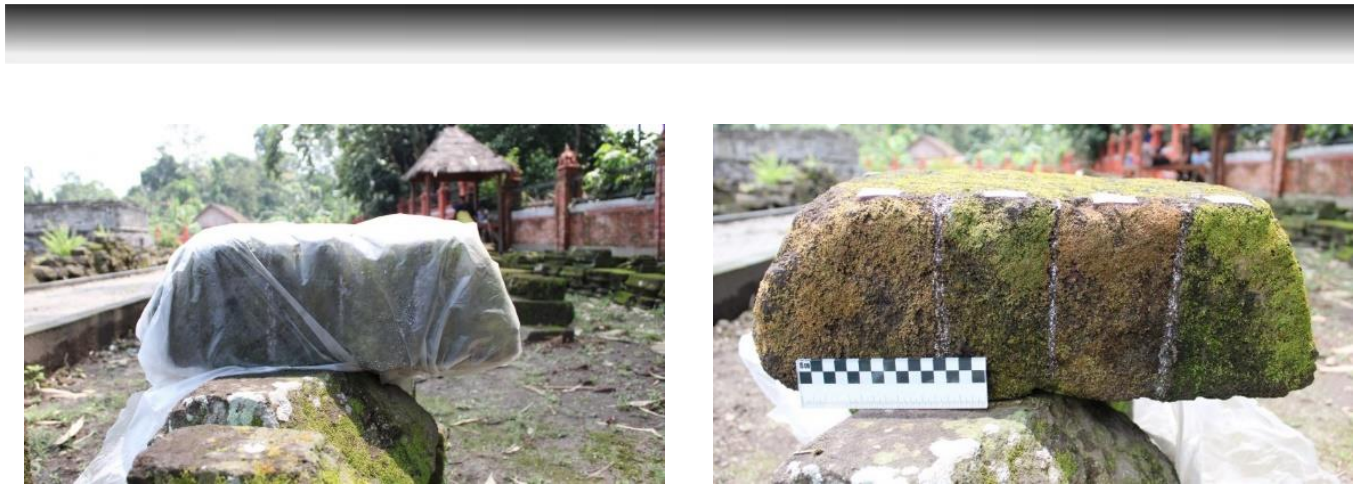

Gambar 2. Gambar Setelah Disemprot Dengan Emulsi Minyak Atsiri, Batu Ditutup Dengan Plastik (gambar kiri) dan Gambar Lumut Setelah 1x24 Jam (gambar kanan) (Sumber: dokumen BPCB Jawa Timur, 2021)

Fungsi penutupan dengan plastik adalah agar emulsi minyak atsiri dapat meresap ke dalam dan bekerja maksimal dalam mematikan organisme lumut, tidak larut jika hujan turun sekaligus menghambat penguapan. Setelah 1 x 24 jam penutup plastik dibuka untuk mengetahui efektivitas bahan minyak atsiri dalam mematikan lumut. Berdasarkan pengamatan didapatkan hasil bahwa emulsi minyak atsiri sereh wangi dan cengkeh konsentrasi $10 \%$ memiliki efektifitas yang sama dalam mematikan lumut, ditandai dengan adanya perubahan warna pada lumut dari hijau menjadi coklat dalam waktu 24 jam. Pengaplikasian minyak atsiri untuk mematikan organisme lumut akan lebih efektif apabila dilakukan pada saat pagi atau siang hari dan diperkirakan tidak akan terjadi hujan sehingga minyak atsiri dapat bekerja secara maksimal. Setelah lumut mati, dapat dilakukan pembersihan mekanis kering dengan sikat ijuk atau lidi. Untuk selanjutnya dilakukan pengamatan secara periodik untuk mengetahui efektifitas dari bahan minyak atsiri tersebut agar dapat ditentukan langkah penanganan berikutnya.

Hasil inventarisasi jenis lumut yang ada di Situs Candi Surowono terlihat pada Gambar 3.

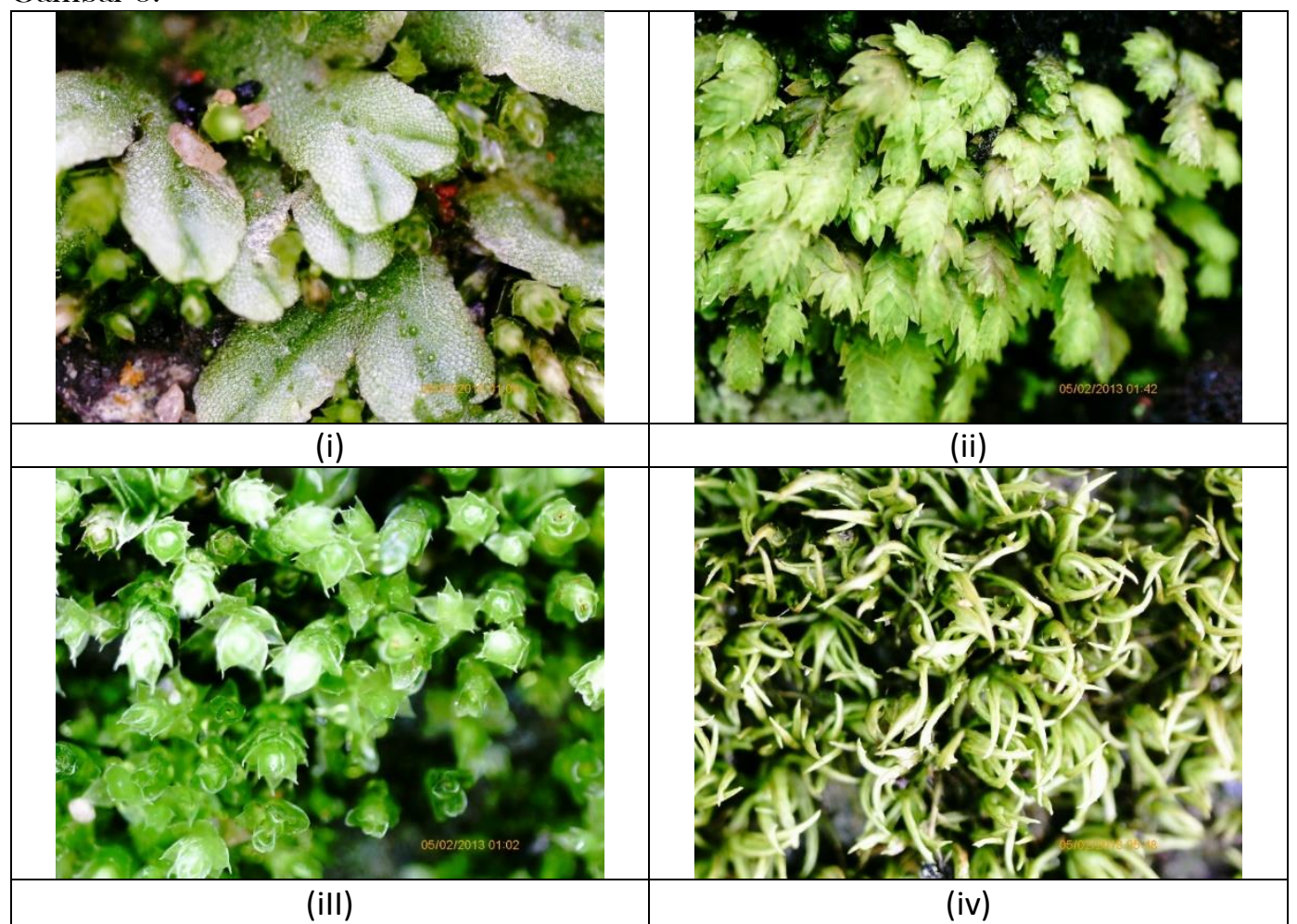

Gambar 3. Gambar lumut (moss) yang terdapat di Situs Candi Surowono

(Sumber: dokumen BPCB Jawa Timur, 2021) 
Pengambilan gambar lumut seperti tampak pada gambar 3, diambil menggunakan alat handy microscope. Gambar 3.(1) termasuk ke dalam golongan lumut hati (Hepaticopsida) (Paryono and Elvi Rusmiyanto Pancaning Wardoyo, n.d.), sedangkan Gambar 3.(ii), (iii) dan (iv) termasuk ke dalam golongan lumut daun (Bryopsida) (Waldi 2017). Perbedaan yang jelas antara lumut hati dan lumut daun adalah bahwa lumut daun, daunnya tumbuh pada semua sisi sumbu utama (simetri radial). Pengaplikasian ketiga minyak atsiri pada batu yang ditumbuhi lumut dilakukan secara acak.

Pengaplikasian minyak atsiri pada lumut kerak (lichen)

Sama halnya seperti lumut, untuk pengaplikasian emulsi minyak atsiri untuk membersihkan organisme lumut kerak (lichen) dipilih satu blok batu yang ditumbuhi oleh lumut kerak. Permukaan blok batu tersebut dibagi menjadi empat bagian untuk disemprotkan ketiga minyak atsiri dan satu untuk kontrol.
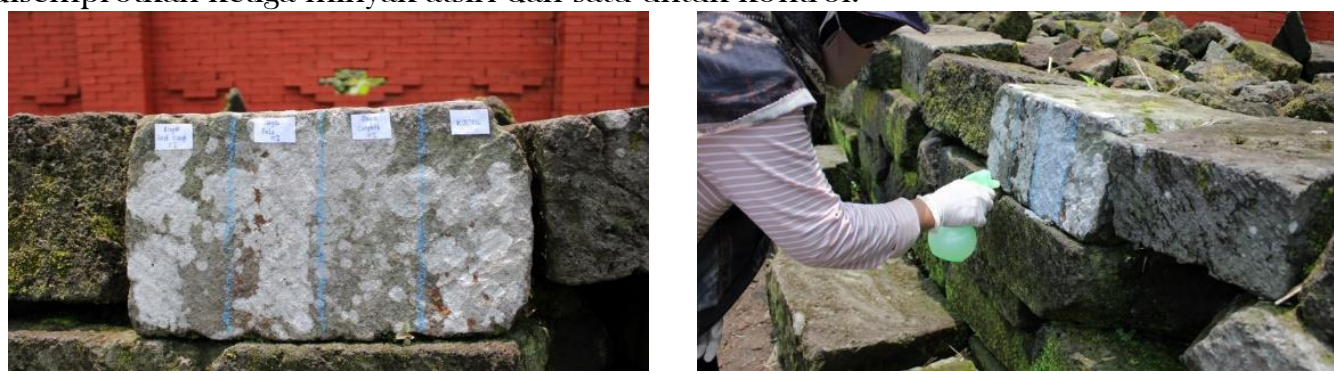

Gambar 4. Gambar Lichen Sebelum Diaplikasi Minyak Atsiri (gambar kiri) dan Gambar Kegiatan Penyemprotan Lichen Dengan Emulsi Minyak Atsiri (gambar kanan) (Sumber: dokumen BPCB Jawa Timur, 2021)

Batu yang ditumbuhi oleh lumut kerak (lichen) setelah disemprot dengan emulsi minyak atsiri kemudian ditutup dengan plastik untuk mencegah terkena air hujan dan mengurangi menguapan. Pengamatan dilakukan setiap 24 jam untuk mengetahui perubahan yang terjadi.

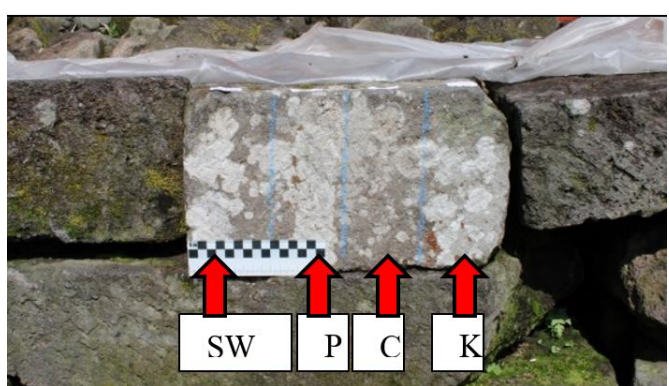

(i)

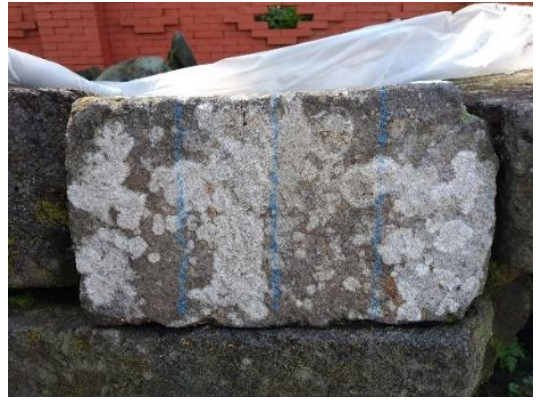

(iii)

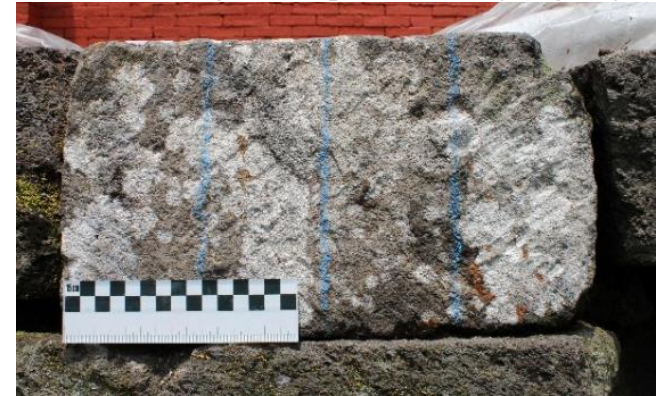

(ii)

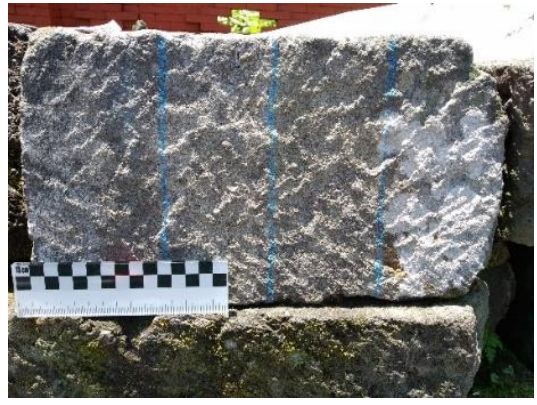

(iv)

Gambar 5. Gambar lichen setelah ditutup plastik selama (i) 24 jam, (ii) 48 jam, (iii) 72 jam, dan (iv) Gambar Lichen Setelah Dibersihkan (Sumber: dokumen BPCB Jawa Timur, 2021) 
Setelah 24 jam penutupan dengan plastik, lichen yang telah disemprot dengan ketiga minyak atsiri dibuka untuk diamati perubahannya. Pengamatan secara visual terhadap lichen yang telah disemprot dengan emulsi minyak atsiri dengan waktu kontak 24 jam menunjukkan bahwa lichen yang diaplikasi dengan emulsi minyak atsiri cengkeh $10 \%$ berubah warna dari putih menjadi putih keabuan. Sedangkan lichen yang disemprot dengan minyak atsiri lain tidak menunjukkan adanya perubahan warna. Setelah pengamatan selesai lichen ditutup kembali dengan plastik. Pengamatan pada hari kedua, menunjukkan hal yang sama seperti hari pertama, dan pada hari ketiga atau 72 jam setelah disemprot menunjukkan lichen yang diaplikasi minyak atsiri cengkeh warna keabuannya semakin merata. Batu yang ditumbuhi lichen kemudian dibersihkan menggunakan sikat nilon/sikat gigi. Hasilnya lichen yang telah diaplikasi minyak atsiri cengkeh lebih mudah dibersihkan dibanding yang lain serta tidak meninggalkan bekas. Hal ini menunjukkan bahwa minyak atsiri cengkeh paling efektif untuk mematikan lichen dibandingkan dengan minyak atsiri lainnya.

Selain pengaplikasian minyak atsiri untuk mengendalikan mikroorganisme lumut kerak (lichen) juga dilakukan identifikasi jenis-jenis lichen yang ada di Situs Candi Surowono. Cara identifikasinya dengan melakukan pengamatan dan pendokumentasian menggunakan handy microscope. Gambar 4 merupakan beberapa organisme lichen yang ada di Situs Candi Surowono baik yang tumbuh di struktur candi maupun pada batuan lepas di sekitar candi.

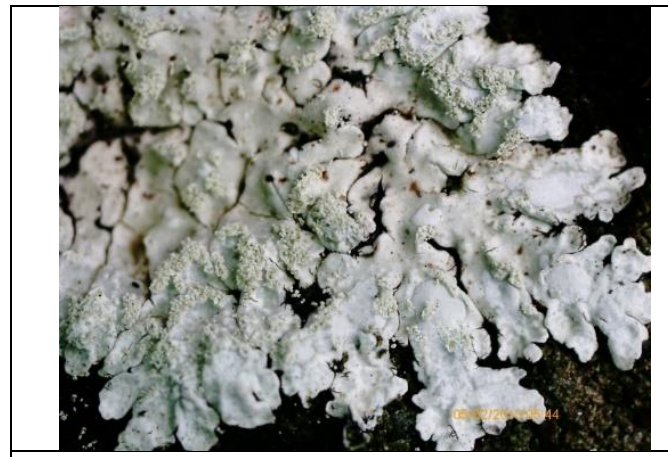

(i)

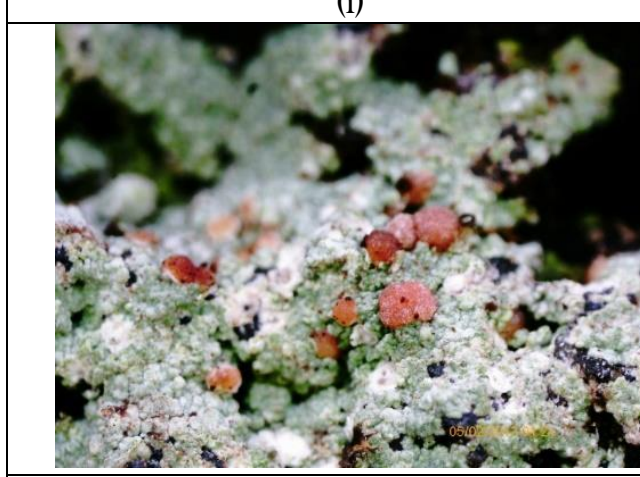

(iii)

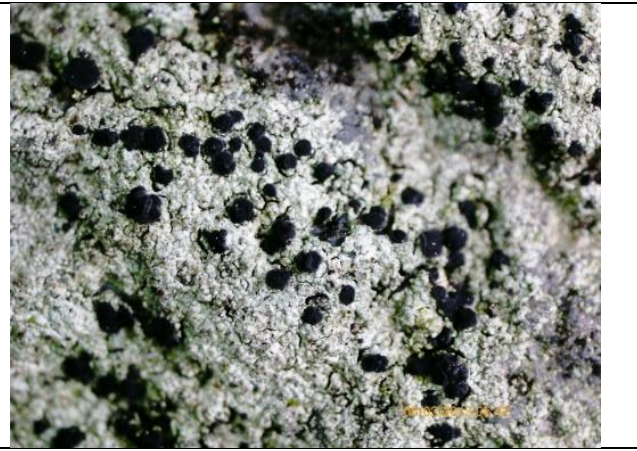

(ii)

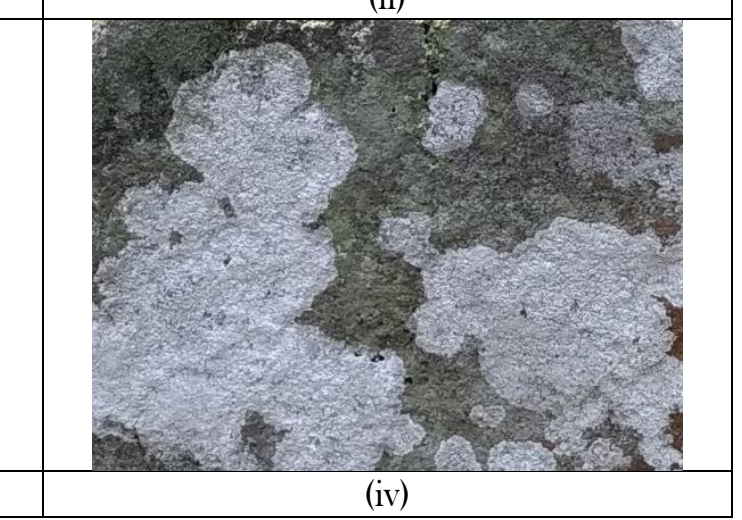

(iv)

Gambar 6. Gambar lichen yang terdapat di Situs Candi Surowono

(Sumber: dokumen BPCB Jawa Timur, 2021)

Gambar 6 menampilkan gambar beberapa lumut kerak yang tumbuh di Situs Candi Surowono. Terdapat 4 jenis lichen yang berhasil dikumpulkan. Berdasarkan morfologi lumut kerak (Iichen) yaitu dari bentuk thallus (tubuh tanaman), lumut kerak yang terdapat pada Situs Candi Surowono pada Gambar 6.(i) termasuk ke dalam jenis foliose. Jenis lumut kerak foliose mempunyai struktur seperti daun yang tersusun lobus-lobus. Jenis lumut kerak 
ini termasuk ke dalam famili Caliciaceae, genus Dirinaria, spesies Dirinaria applanata (Asyifa and Roziaty 2018). Lichen pada gambar 6.(ii) berwarna putih dengan terdapat bulatan hitam di atasnya termasuk famili Arthoniaceae, dengan spesies Arthonia sp (Murningsih and Mafazaa 2016). Jenis Arthonia sp. ini termasuk ke dalam golongan tipe tallus crustose (Panjaitan and Martina 2012). Gambar 6.(iii) dan 5.(iv) adalah tipe lichen yang termasuk ke dalam tipe crustose yang memiliki talus berukuran kecil, berbantuk datar, tipis dan selalu melekat pada permukaan batu, kulit atau tanah. Sedangkan jenisnya belum teridentifikasi. Berdasarkan habitatnya, lumut kerak (Iichen) yang terdapat pada Situs Candi Surowono termasuk ke dalam kategori Saxicolous, yaitu jenis lichen yang tumbuh pada substrat batuan.

Tipe lichen yang telah diaplikasi dengan emulsi minyak atsiri pada batu candi di Situs Candi Surowono adalah gambar 6.(iv) yang bertipe crustose. Pada beberapa kasus pengaplikasian minyak atsiri pada material cagar budaya khususnya batu andesit yang ditumbuhi lichen, menunjukkan adanya efektivitas bahan minyak atsiri yang berbeda. Lichen yang disemprot dengan minyak atsiri ada yang mati setelah kontak selama 24 jam dan ada yang sama sekali tidak berpengaruh. Efektivitas dari bahan minyak atsiri ini kemungkinan besar dipengaruhi oleh jenis lichennya. Lichen merupakan organisme gabungan dari ganggang dan jamur. Kematian lichen dipengaruhi oleh sensitivitas dari organisme ganggang dan jamur terhadap minyak atsiri. Jika organisme ganggang dan jamur penyusun lichen memiliki sensitivitas tinggi terhadap minyak atsiri yang diaplikasi maka lichen akan mati sedangkan jika tidak sensitif maka lichen akan tetap hidup. Jadi dalam pengendalian lichen dengan minyak atsiri membutuhkan ujicoba dan pengamatan sehingga dapat diketahui efektivitas bahannya.

Lichen merupakan organisme pioner yang akan tetap bisa hidup dalam lingkungan yang ekstrem (Roziaty and Utari 2017). Selain itu lichen memiliki tingkat adaptasi dan toleransi yang tinggi terhadap faktor lingkungan seperti suhu udara, kelembaban udara, dan intensitas udara (Hadiyati and Tri Rima Setyawati 2013). Intensitas cahaya terendah yang diperlukan lumut kerak untuk fotosintesis secara efektif adalah 1025 lux (Showman 1972).

Lumut kerak (lichen) membutuhkan suhu optimal yaitu di bawah $40^{\circ} \mathrm{C}$ untuk tumbuh, suhu di atas $45^{\circ} \mathrm{C}$ dapat merusak klorofil pada lichen dan proses fotosintesis menjadi terganggu. Kelembaban udara merupakan faktor penting bagi organisme lumut kerak (lichen) dalam menyerap nutrisi dari atmosfer. Organisme lichen banyak menyukai lingkungan yang kering dengan kelembaban yang berkisar antara 40\%-69\% (Furi and Roziaty 2016). Lingkungan dengan kelembaban udara yang lembab (85\%), lichen dapat tumbuh dan berfotosintesis, sedangkan di atas $85 \%$ dapat mengurangi efektifitas fotosintesis lichen sebesar 35-40\% (Renhorn et al. 1996).

Tabel 1. Suhu dan Kelembaban Udara Candi Surowono 2021

\begin{tabular}{llcc} 
No. & \multicolumn{1}{c}{ Parameter } & \multicolumn{2}{c}{ Lokasi } \\
\cline { 3 - 4 } & & Candi Surowono & Pos Satpam \\
\hline 1. & Suhu udara maksimal $\left({ }^{\circ} \mathrm{C}\right)$ & 35,2 & 34,4 \\
\hline 2. & Suhu udara minimal $\left({ }^{\circ} \mathrm{C}\right)$ & 25,2 & 25,3 \\
\hline 3. & Suhu udara rata-rata $\left({ }^{\circ} \mathrm{C}\right)$ & 27,5 & 28,9 \\
\hline 4. & Kelembaban maksimal $(\%)$ & 93,7 & 88,3 \\
\hline 5. & Kelembaban minimal $(\%)$ & 76,5 & 65,4 \\
\hline 6. & Kelembaban rata-rata $(\%)$ & 89,2 & 79,3 \\
\hline
\end{tabular}

(Sumber: dokumen BPCB Jawa Timur, 2021)

Berdasarkan tabel 1. terlihat bahwa suhu udara rata-rata antara di bangunan Candi Surowono dan di dalam ruang Pos Satpam tidak berbeda jauh yaitu $27^{\circ} \mathrm{C}$ dan $28,9{ }^{\circ} \mathrm{C}$. Sedangkan kelembaban udara rata-rata adalah $89,2 \%$ di candi dan 79,3\% di dalam ruang Pos Satpam area candi. Pada kondisi lingkungan tersebut lichen dapat berkembang dengan baik. 
Hasil pengamatan menunjukkan keberadaan lumut kerak (lichen) lebih banyak tumbuh pada batuan lepas dibandingkan pada bangunan Candi Surowono.

\section{KESIMPULAN}

Lumut (moss) dan lumut kerak (lichen) merupakan organisme yang sering dijumpai tumbuh pada bangunan cagar budaya. Mikroorganisme ini merupakan salah satu penyebab kerusakan pada bangunan candi baik berbahan batu maupun bata. Lumut banyak tumbuh pada kondisi lingkungan yang lembab. Akar lumut dan lichen yang menempel pada pori batuan dapat mempercepat proses degradasi batu. Lichen berkontribusi dalam pelapukan secara mekanik pada batu salah satunya karena hifa dari lichen dapat meresap ke dalam batu hingga kedalaman 15-20 mm (Clair and Seaward 2004). Hasil pengaplikasian ketiga minyak atsiri yaitu sereh wangi, pala dan cengkeh untuk membersihkan lumut yang tumbuh di Situs Candi Surowono menunjukkan bahwa emulsi minyak atsiri sereh wangi 10\% dan cengkeh $10 \%$ efektif untuk membersihkan lumut, ditandai adanya perubahan warna lumut dari hijau menjadi kecoklatan dengan waktu kontak 24 jam. Sedangkan pada lichen menunjukkan bahwa emulsi minyak atsiri cengkeh konsentrasi 10\% paling efektif untuk mematikan lichen, ditandai dengan adanya perubahan warna pada lichen dari putih menjadi putih keabuan dalam waktu 72 jam ditutup dengan plastik dan pembersihannya lebih mudah dibandingkan dengan minyak atsiri lain. Selanjutnya dilakukan pengamatan secara periodik untuk mengetahui efektifitas dari bahan minyak atsiri tersebut agar dapat ditentukan langkah penanganan berikutnya. Menjawab tujuan dari penelitian ini bahwa penggunaan bahan minyak atsiri ini dapat menjadi alternatif pengganti bahan kimia pabrikan yang selama ini sering dipakai. Untuk melihat efektifitas bahan minyak atsiri khususnya untuk membersihkan lichen yang tumbuh pada bangunan cagar budaya perlu diuji coba terlebih dahulu meningingat lichen merupakan simbiosis 2 organisme antara jamur (fungt) dan ganggang (algae) yang jenisnya juga beragam sehingga memiliki sensitivitas yang berbeda terbadap bahan yang diaplikasi.

\section{UCAPAN TERIMA KASIH}

Ucapan terima kasih kepada Drs. Zakaria Kasimin, Kepala Balai Pelestarian Cagar Budaya Jawa Timur yang telah memberikan kesempatan untuk melaksanakan kegiatan bersama di Situs Candi Surowono, Dusun Surowono, Desa Canggu, Kecamatan Badas, Kabupaten Kediri, Jawa Timur.

\section{DAFTAR PUSTAKA}

Asyifa, Isnaini Zakiyyah, and Efri Roziaty. 2018. "Kajian Distribusi Tanaman Lumut Kerak (Lichenes) Pada Pohon Angsana Di Kawasan Universitas Sebelas Maret, Kentingan, Surakarta.” Universitas Muhammadiyah Surakarta.

BPCB Jawa Timur. 2016. "Laporan Konservasi Candi Surowono Di Kabupaten Kediri."

Conti, Marcelo Enrique, and Gaetano Cecchetti. 2001. "Biological Monitoring: Lichens as Bioindicators of Air Pollution Assessment-a Review.” Environmental Pollution 114 (3): 471-92.

Furi, Ade Ratna, and Efri Roziaty. 2016. "Eksplorasi Lichen Di Sepanjang Jalan Raya Solo Tawangmangu Dan Kawasan Hutan Sekipan Karanganyarjawa Tengah.” UNIVERSITAS MUHAMMADIYAH SURAKARTA. 
Hadiyati, Mursina, and Mukarlina Tri Rima Setyawati. 2013. "Kandungan Sulfur Dan Klorofil Thallus Lichen Parmelia Sp. Dan Graphis Sp. Pada Pohon Peneduh Jalan Di Kecamatan Pontianak Utara.” Protobiont 2 (1).

Mulyani, Eka, Lilih Khotim Perwati, and Murningsih Murningsih. 2014. "Lumut Daun Epifit Di Zona Tropik Kawasan Gunung Ungaran, Jawa Tengah.” Bioma: Berkala Ilmiah Biologi 16 (2): 76-82.

Murningsih, Murningsih, and Husna Mafazaa. 2016. "Jenis-Jenis Lichen Di Kampus Undip Semarang.” Bioma: Berkala Ilmiah Biologi 18 (2): 20-29.

Panjaitan, Desi Maria, and Atria Martina. 2012. "Keanekaragaman Lichen Sebagai Bioindikator Pencemaran Udara Di Kota Pekanbaru Provinsi Riau."

Paryono, Agus, and Mukarlina Elvi Rusmiyanto Pancaning Wardoyo. n.d. "Inventarisasi Lumut Hati Bertalus Kompleks (Kelas Marchantiopsida) Di Taman Kota Pontianak.” Protobiont 6 (2).

Pratiwi, Mungki Eka. 2006. "Kajian Lumut Kerak Sebagai Bioindikator Kualitas Udara Studi Kasus: Kawasan Industri Pulo Gadung, Arboretum Cibubur Dan Tegakan Mahoni Cikabayan.”

Purawijaya, Dandri Aly, and Adinda Gita Priyantika. 2013. "Biological Assesment Pertumbuhan Lumut Di Candi Borobudur Pada Sisi Utara Dan Selatan Lorong 2.” Jurnal Konservasi Cagar Budava Borobudur 7 (1).

Renhorn, K-E, Per-Anders Esseen, Kristin Palmqvist, and Bodil Sundberg. 1996. "Growth and Vitality of Epiphytic Lichens." Oecologia 109 (1): 1-9.

Rosentreter, Roger, Matthew Bowker, and Jayne Belnap. 2007. "A Field Guide to Biological Soil Crusts of Western US Drylands: Common Lichens and Bryophytes.” Bureau of Land Management, 1.

Roziaty, Efri, and Ratih Tri Utari. 2017. "Jenis Dan Morfologi Lichen Fruticose Di Kawasan Hutan Sekipan Desa Kalisoro Tawangmangu Karanganyar Jawa Tengah.” In Proceeding Biology Education Conference: Biology, Science, Enviromental, and Learning, 14:114-17.

Showman, Ray E. 1972. "Photosynthetic Response with Respect to Light in Three Strains of Lichen Algae."

Waldi, Ryo. 2017. "Inventarisasi Lumut Di Kawasan Perkebunan Karet Ptpn 7 Desa Sabah Balau, Kabupaten Lampung Selatan, Lampung.” UIN Raden Intan Lampung. 